\title{
A CASE OF FAMILIAL BILATERAL ANOPHTHALMOS WITH SYNDACTYLY
}

Ganesh T. Waghmode

1. Assistant Professor, Department of Anatomy, Rajiv Gandhi Institute of Medical Sciences, Srikakulam.

\section{CORRESPONDING AUTHOR}

Dr. Ganesh. T. Waghmode.

Plot.No.-72. A.S.N. Colony,

Srikakulam (A.P)

PIN NO-532001

E-mail: gw1726@gmail.com

Ph: 0091 9441799328,

ABSTRACT: The congenital disorder anophthalmos is very rare. In this condition, ocular tissue is absent within the orbit.

In microphthalmos a very small globe is present within the orbit. Microphthalmos is more common.

In this study, I report bilateral anophthalmos with syndactyly. This report discusses anatomy, etiology, diagnosis and embryological basis of this anatomical variation with relevant review of literature.

KEY WORDS: Anophthalmos, ocular tissue, microphthalmos, syndactyly, bilateral anophthalmia.

MESH TERMS: Anophthalmos-UID-D000853, Syndactyly-UID-D013576

INTRODUCTION: Anophthalmos and microphthalmos are an important causes of visual impairment. Familial transmission of chromosomal defect is main etiological factor in congenital bilateral anophthalmia.

CASE REPORT: A still born male foetus of 35 weeks of gestation was referred to the department of Anatomy.

Congenital disorders were not seen in the family of mother. Father had bilateral anophthalmia with polydactyl. There was no history of consanguinity.

Pregnancy and labour had been normal.

Prenatally foetus was diagnosed as anophthalmos of right eye and syndactyly of left foot.

\section{EXAMINATION FINDINGS WERE AS FOLLOWS:}

- The eyelids and palpebral aperture were absent in right eye.

- Very short eyelids and just slit like palpebral aperture were present in left eye. (Fig - 1).

- Syndactyly of left foot was present (fig - 2).

- All remaining organs were normal

\section{DISSECTION FINDINGS WERE AS FOLLOWS:}


- Globe of the eye and extraocular muscles were absent in both the eyes.(fig-3)

- Optic chiasma and optic tracts were absent.

- The brain was normal.

HISTOLOGICAL EXAMINATION: Ocular tissue was absent in both the eyes on histological examination.

KARYOTYPING: I was unable to do the karyotyping of stillborn foetus. Karyotypes of his father showed deletion on long arm of 14q22q23.

DISCUSSION: Congenital anophthalmos is very rare condition with prevalence rate 0.18 per 10000 births [5].

Bilateral anophthalmos may have an associated absence of the optic chiasma, a diminished size of the posterior pathways, as well as agenesis of the corpus callosum. [ 2 ].

Ahmad ME et al. reported that deletion on long arm of $14 \mathrm{q} 22 \mathrm{q} 23$ is responsible for anophthalmos and preaxial polydactyly. Their case report appear to be similar to those found in my case report, except that there was polydactyly in their case report. [1].

Bakrania $\mathrm{p}$ et al. reported that sox2 haplosufficiency is cause of anophthalmos with oesophageal variations and horseshoe kidney in their case report. [3].

Brunquell PJ et al reported a case with $\mathrm{x}$ linked bilateral anophthalmos. In their case optic globe, nerves and optic chiasma was absent. Rudimentary optic tracts, gliotic lateral geniculate nuclei, thinner calcarine cortex was present, but in my case brain was normal. [4].

Albernaz vs. et al. reported use of transvaginal ultrasound in the diagnoses of anophthalmos. [2].

EMBRYOLOGICAL BASIS: Anophthalmos occurs when the neuroectoderm of the primary optic vesicle fails to develop properly from the anterior neural plate of the neural tube during embryological development.

The more commonly seen microphthalmos can result from a problem in development of the globe at any stage of growth of the optic vesicle. [6].

CONCLUSION: Karyotyping, genetic counseling and transvaginal ultrasound can avoid familial anophthalmos.

\section{REFERENCES:}

1. Ahmad ME, Dada R, Dada T, Kucheria K. 14q (22) deletion in a familial case of anophthalmia with polydactyly. Am J Med Genet A. Jul 1 2003; 120 (1) : 117-122.

2. Albernaz VS, Castillo M, Hudgins PA, Mukherji SK. Imaging findings in patients with clinical anophthalmos. AJNR AMJ Neuroradiol. Mar 1997; 18(3): 555-561

3. Bakrania P, Robinson DO, Bunyan DJ, Salt A, Martin A, Crolla JA, Wyatt A, Fielder A, Ainsworth J, Moore A, Read S, Uddin J, Laws D, Pascuel S D, Ayuso C, Allen L, Collin JR, Ragge NK. SOX2 anophthalmia syndrome : 12 new cases demonstrating broader phenotype and high frequency of large gene deletions. Br J Ophthalmol. Nov 2007: 91(11): 1471-1476. 
4. Brunquell PJ, Papale J H, Horton JC, Williams RS, Zgrabik MJ, Albert DM, HedleyWhyte ET. Sex- linked hereditary bilateral anophthalmos. Arch ophthalmol. 1984; 102 (1) : 108-113.

5. Shaw GM, Carmichael SL, Yang W, Harris JA, Finnell RH, Lammer EJ. Epidemiologic Characteristics of anophthalmia and bilateral microphthalmia among 2.5 million births in California, 1989-1997. Am J Med Genet A. Aug 15 2005; 137(1): 36-40.

6. Trivedi HL, Ramesh Venkatesh. Anophthalmos. Bombay Hospital Journal. 2009; 51 (1) : 80-84.

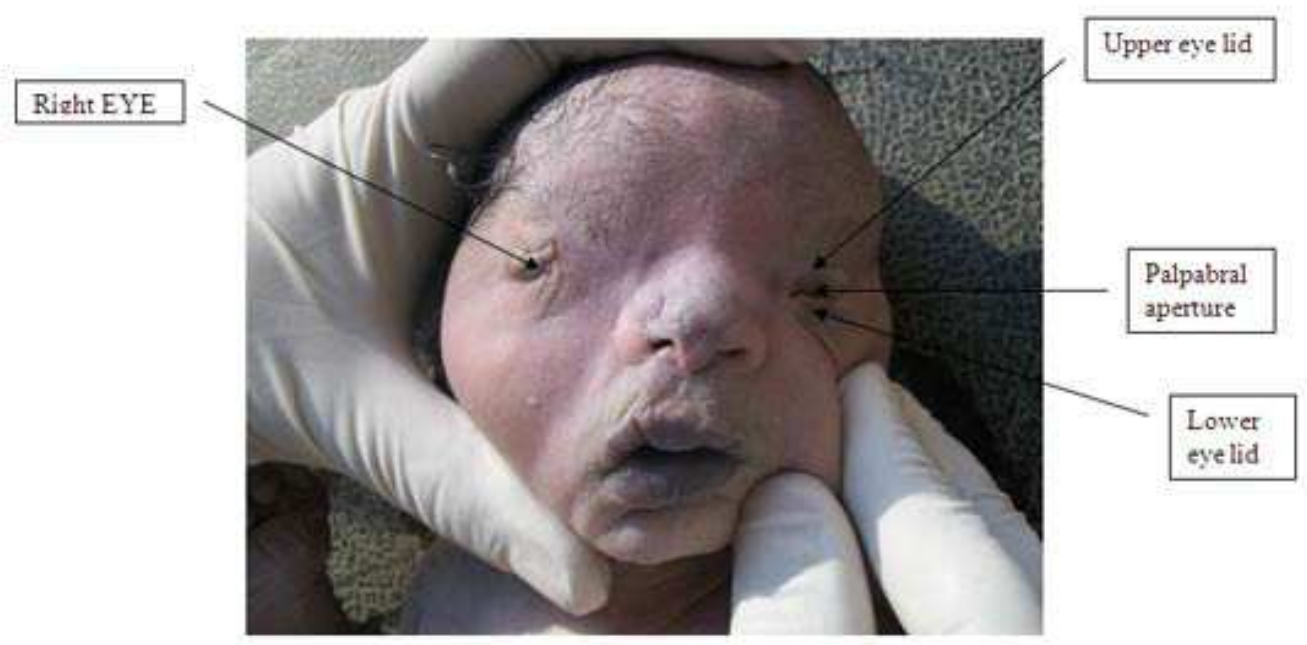

Figure-1

Right eye eyelids absent. Left eye eyelids are very short

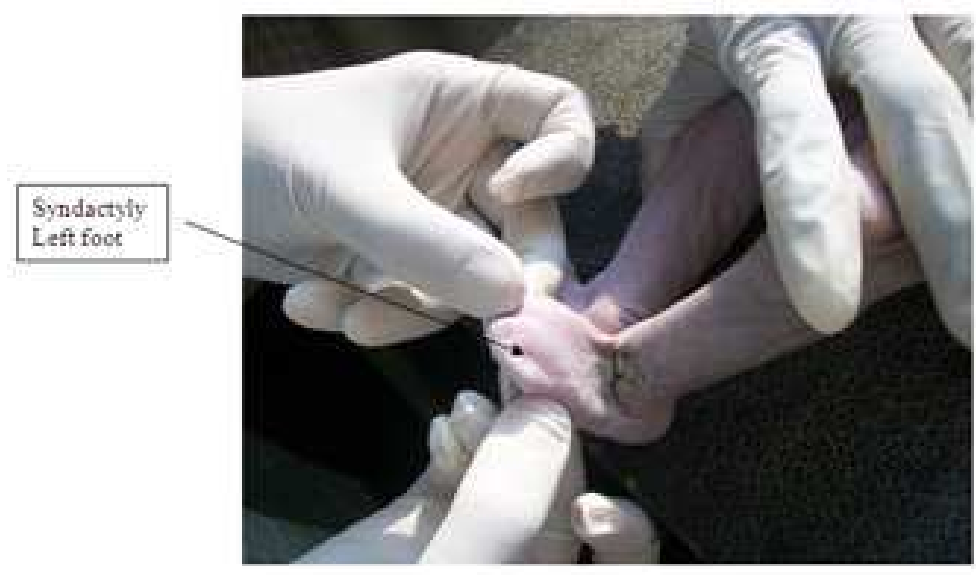

Figure - 2

Syndactyly of Left foot 


\section{CASE REPORT}

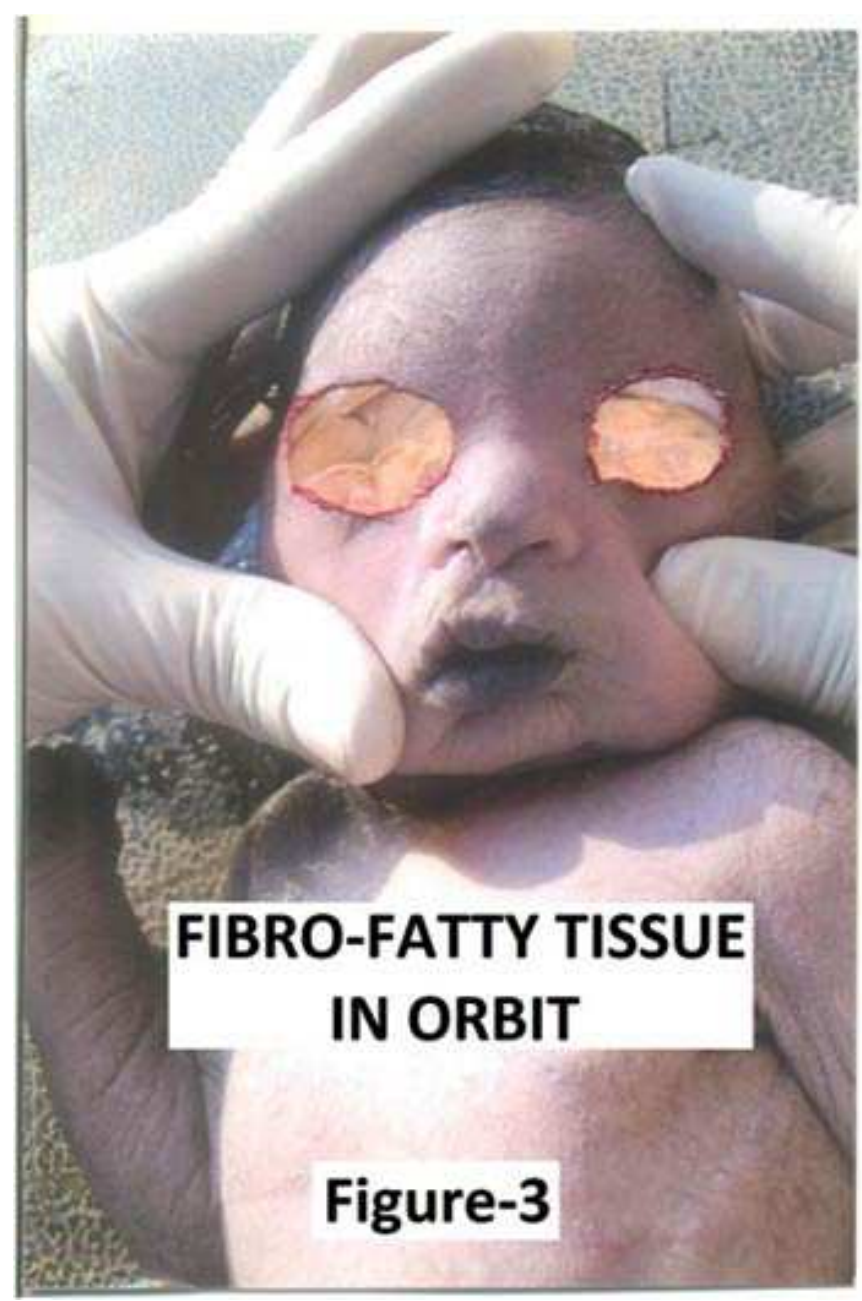

